\title{
Ultrasonic Impact Treatment of the Welded Joint of Aluminum-Magnesium Alloy Produced by Friction Stir Welding
}

\author{
Evgeny Kolubaev $^{1,2, a)}$, Alexander Kolubaev ${ }^{1,2, b)}$, Olga Sizova ${ }^{1,2, c)}$, \\ Valery Rubtsov ${ }^{1, d)}$, Aleksey Tolmachev ${ }^{1, \text { e) }}$, and Sergey Psakhie ${ }^{1,2, \text { f) }}$ \\ ${ }^{1}$ Institute of Strength Physics and Materials Science SB RAS, Tomsk, 634055, Russia \\ ${ }^{2}$ National Research Tomsk Polytechnic University, Tomsk, 634050, Russia \\ a) Corresponding author: eak@ispms.ru \\ ${ }^{b)}$ kav@ispms.ru \\ c) ovs@ispms.ru \\ d) rvy@ispms.ru \\ e) tolmash@ispms.ru \\ f) $\mathrm{sp} @$ ispms.ru
}

\begin{abstract}
The paper presents the results of ultrasonic impact treatment of the $\mathrm{AMg} 5 \mathrm{M}$ alloy weld joint produced by friction stir welding, in order to eliminate defects in the root side of the weld. It was shown that ultrasonic impact treatment increases the microhardness of the surface layer caused by the accumulation of microplastic deformation during the impact.
\end{abstract}

Keywords: friction stir welding, aluminum alloy, microstructure, deformation, plastic flow, ultrasonic impact treatment

\section{INTRODUCTION}

Plastic deformation of metal is used in metal forming by rolling, forging and extrusion in order to modify the structure of the material and improve the physical and mechanical properties of products. Ultrasonic impact treatment relates to methods of plastic deformation, but it is limited by the deformation in the subsurface of a material. For a long time, this method has been used in engineering for hardening and finishing surfaces of equipment components. Rapidly alternating compression and shear contact stresses alter the physical and mechanical state of the surface layer and modify the surface roughness, microhardness, residual stress level, etc. to improve its strength and service characteristics. In addition, ultrasonic impact treatment was successfully used for relieving the internal stress in steel welded joints that also lead to the improvement of the mechanical properties of products.

Ultrasonic impact treatment of welded aluminum alloy structures is not widely used in practice, but there is the evidence of its positive effect on the fatigue strength of products $[1,2]$. The high-frequency impact treatment refines the grain structure of aluminum alloys and even heals the microcracks and pores thus improving the surface hardness and fatigue strength of the treated materials. It can be expected that the ultrasonic impact treatment of the aluminum alloy welded joints produced by friction stir welding would also improve their strength and performance primarily due to inducing the compression stress instead of residual tensile one.

Studying the structure of the welded joint produced by friction stir welding allows revealing its specific structure, which determines the mechanical properties of the welded joint. It is noted that the cross-sectional view of the friction stir welding weld nugget is asymmetric relative to the weld joint centerline [3].

International Conference on Physical Mesomechanics of Multilevel Systems 2014

AIP Conf. Proc. 1623, 271-274 (2014); doi: 10.1063/1.4901486

(C) 2014 AIP Publishing LLC 978-0-7354-1260-6/\$30.00 


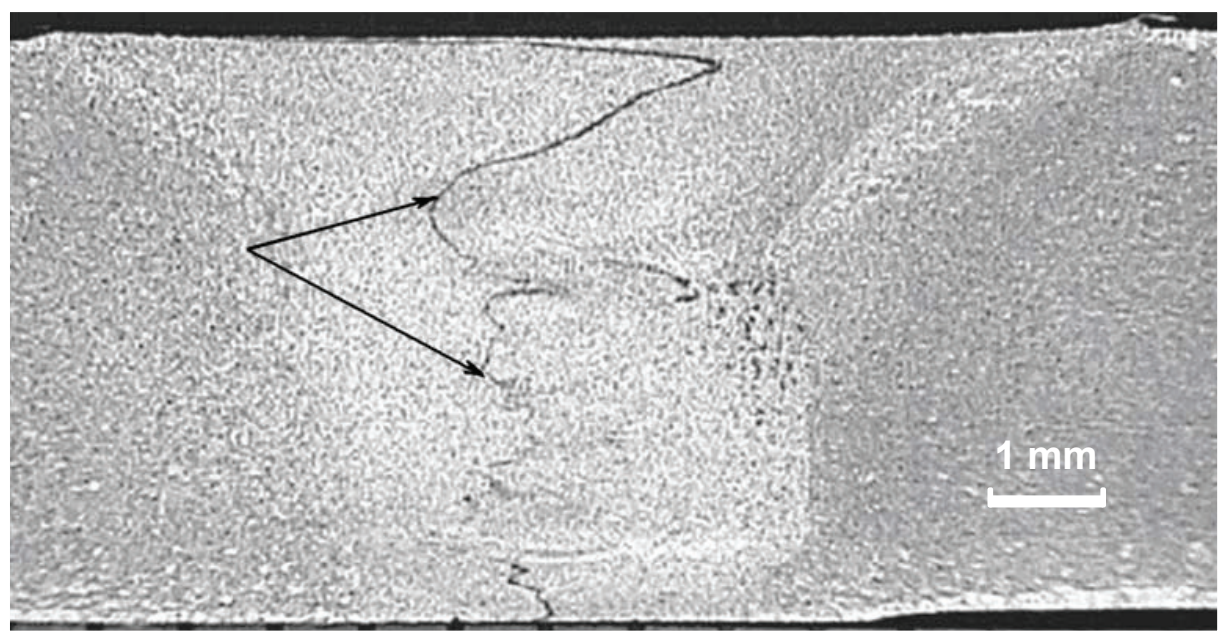

FIGURE 1. Accumulation of oxides in welded joint area (indicated by arrows)

Furthermore, it is characterized by a layered structure consisting of alternating strips $[4,5]$ with ultrafine grain structure. Such ultradispersed structure is formed due to the fragmentation during severe plastic deformation combined with recrystallization. Another feature of the weld that is often found during studying the cross-sectional microstructure is the oxide chains [6] forming a curved surface between the layers (Fig. 1). All these features have their effect on fracturing the welded joints produced by friction stir welding. The fracturing during static tensile test starts from the weld root due to the crack formation and passes along the curved line shown in Fig. 1, which is decorated by oxides [7]. There are various ways of eliminating these defects, for example, by heating the welded sheets or welding by two opposite pins. Such an approach allows obtaining an improved and more durable welded joint.

Another way to improve the quality of the friction stir welding welded joints has been proposed [8], where the friction stir welding tool is driven by ultrasonic impact during the friction stir welding. As a result, there was a decline in the force of friction welding, as well as the increased plasticity of the welded joint in the tensile test.

The aim of the present work is to study the possibility of using the ultrasonic impact treatment for eliminating the friction stir welding weld root flaws in AMg5 alloy.

\section{MATERIAL AND EXPERIMENT TECHNIQUE}

Studies were performed using the samples of $\mathrm{AMg} 5 \mathrm{M}$ aluminum alloy. The butt weld samples of sheets were prepared using the technique described in [9]. The thickness of the sheet to be welded was $5 \mathrm{~mm}$, and the weld sample width after welding was $185 \mathrm{~mm}$. The length of the welded joints produced using different welding modes varied from 100 to $1020 \mathrm{~mm}$. The circular shape samples for ultrasonic impact treatment were cut from the samples so that the weld joint was positioned along the diameter of the circle.

Ultrasonic impact treatment of the surface of samples was performed using the USTK-18/22 device operated at the power of $200 \mathrm{~W}$. The tool was fixed on a lathe thus making it possible to change the speed of the surface impact treatment by changing both rotation and feed rates. The tip of the tool was made of spherical WC-Co hard metal and actuated by $22 \mathrm{kHz}$ oscillations with the amplitude of about 15 microns. The disk-shaped test samples with an 80 $\mathrm{mm}$ diameter and a $5 \mathrm{~mm}$ thickness were placed on a substrate of the same diameter and then mounted on the spindle of the lathe. Then the weld root of the rotating sample was subjected to the treatment.

After the ultrasonic impact treatment the discs were cut into parallelepipeds using a spark erosion machine for metallographic examination of the cross section. The structure of the welded joint was revealed by multiple polishing and etching in a mixture of nitric and hydrochloric acid diluted by water. Investigation of the microstructure of the weld joint was carried out using METAM LV-31 optical microscope. Crystalline structure was studied using Shimadzu XRD-6000 system. The microhardness was measured using PMT-3M device with the load of $0.5 \mathrm{~N}$. 


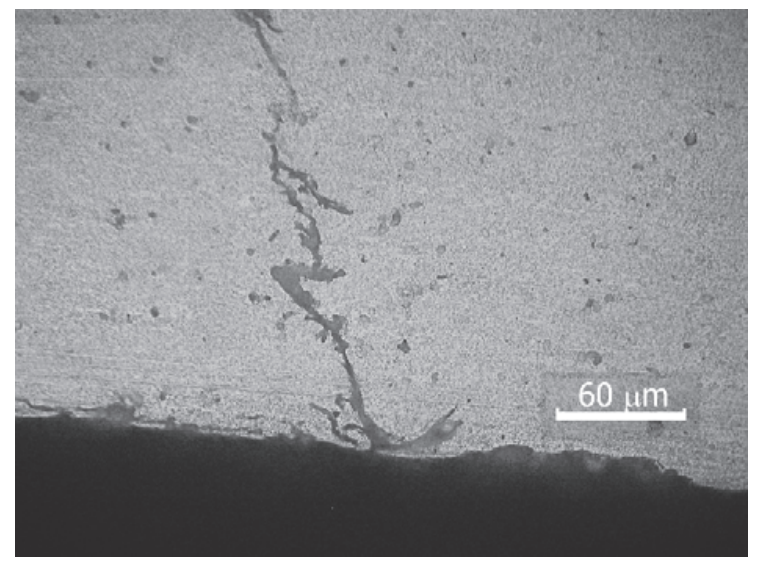

FIGURE 2. Accumulation of oxides in weld, preserved after ultrasonic impact treatment

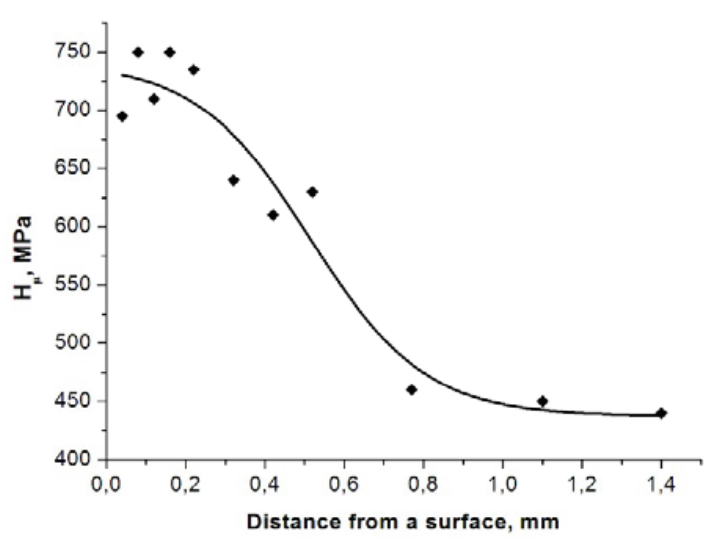

FIGURE 3. Microhardness of surface layer at weld root after ultrasonic impact treatment

\section{RESULTS AND DISCUSSION}

As noted above, during the friction stir welding the joint area suffers the accumulation of oxides that form a curved surface along the weld joint. The reason for such a defect formation is the oxide film on the butt end surfaces of aluminum sheets, which does not dissolve during the friction stir welding, but gets dispersed with the formation of oxide inclusions. During the mechanical loading of such a welded joint, fracture usually occurs along this surface.

To increase the strength of the weld joint, it is a common practice to apply milling to the end surfaces of the welded sheets, thus allowing removal of the oxide film. The preheating of the weld root in the welding process is applied too, thus providing a higher quality of the welded joint.

In the present work, we have studied the structure of the welded joints that had their root side surface exposed to ultrasonic impact treatment. It was assumed that during plastic deformation, the metal oxide line would be fragmented, and the fragments would admix into the weld root with formation of a more perfect microstructure. Similar approach was applied to the layer of cemented steel with a grain boundary cementite network to improve the inhomogeneous structure by ultrasonic impact treatment [10].

It was found that the effect of ultrasonic impact treatment on the cemented steel layer resulted in a modified refined structure, more uniform grain size distribution and fragmentation of the cementite network. However, the surface treatment of the aluminum alloy weld root did not lead to the intermixture of the metal oxides (Fig. 2).

Since ultrasonic impact action is dampening with the depth, it can be used as a model of coherent structure modification by the relaxation of loading. Indeed, the microhardness measurement of the surface layer of the aluminum-magnesium alloy sample after ultrasonic impact treatment showed an increase of the hardness at the depth of up to $600 \mu \mathrm{m}$ below the surface (Fig. 3). This indicates the modification of the structure. However, as shown by the metallographic examination, the root side of the welded joint after the treatment had no visible changes in the microstructure as compared to the original sample. Furthermore, as noted above, the interface formed by the accumulation of oxides inside the joint remained (Fig. 2).

Phase composition of the alloy and the residual stresses were studied by X-ray diffraction and showed that the weld material had a two-phase structure that was confirmed by the literature information on the retaining phase composition of the aluminum alloy after friction stir welding. However, it is interesting that after the ultrasonic impact treatment the amount of intermetallic phase increased (Fig. 4(a, b)). Apparently, partial dissolution of solid particles occurs with the diffusion of magnesium to matrix due to a high temperature generated during the friction stir welding. The ultrasonic impact treatment thus served to dissolve the inclusions.

The subsurface plastic deformation of the sample in the direction perpendicular to its surface has been determined by X-ray diffraction. To find the microstrain level, it is necessary to determine the changes of interplanar distance between atomic planes parallel to the surface of the sample as $\varepsilon=\Delta d / d$. Evaluation of average internal microstresses showed that without ultrasonic treatment it amounted to $0.47 \mathrm{GPa}$ after the friction stir welding. The ultrasonic surface impact treatment led to the increase of the microstress level up to $0.65 \mathrm{GPa}$. Accordingly, the size of coherent scattering areas changed from $100 \mathrm{~nm}$ before ultrasonic treatment to $80 \mathrm{~nm}$ after the ultrasonic treatment. This indicates an additional fragmentation of the grain structure. 


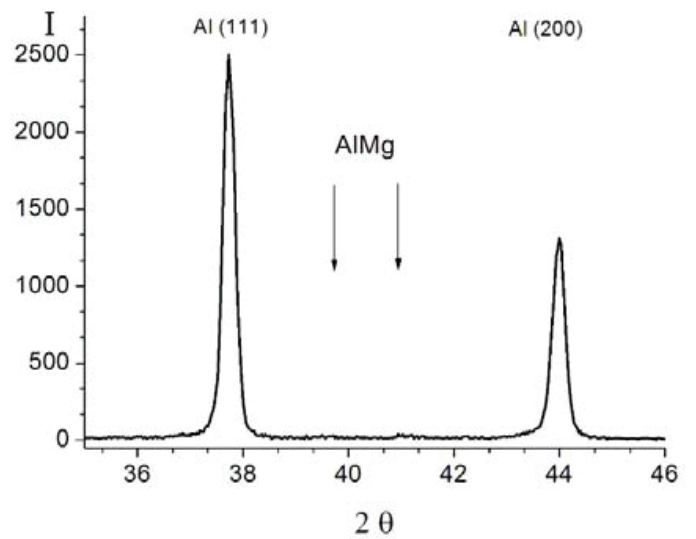

(a)

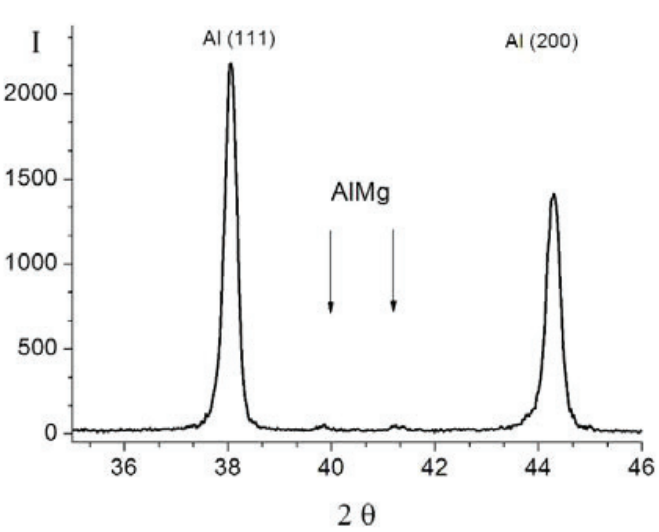

(b)

FIGURE 4. X-ray diffraction of the root weld: (a) untreated; (b) after ultrasonic impact treatment

Accordingly, the size of coherent scattering areas changed from $100 \mathrm{~nm}$ before ultrasonic treatment to $80 \mathrm{~nm}$ after the ultrasonic treatment. This indicates an additional fragmentation of the grain structure.

\section{SUMMARY}

The work represents the initial application of the ultrasonic impact treatment technology in attempt to improve the mechanical properties of friction stir welds. The results indicate that this technology can be used either as a finishing operation as described in this work or as a supplementary treatment during the welding process [7].

\section{ACKNOWLEDGEMENT}

The work has been supported by RF Ministry of Education and Science (project ID RFMEFI57814X0045) on "Improving the technology of friction stir welding by ultrasonic treatment to form permanent connections of hardened aluminum alloy for aerospace and transport industry" and by Program for Basic Scientific Research of the State Academy of Science on 2013-2020.

\section{REFERENCES}

1. C. A. Rodopoulos, Sp. G. Pantelakis, and M. P. Papadopoulos, J. Mater. Eng. Perform. 9(18), 1248 (2009).

2. H. Gao, R. K. Dutta, R. M. Huizenga, M. Amirthalingam, M. J. M. Hermans, T. Buslaps, and I. M. Richardson, Sci. Tech. Weld. Join. 6(19), 505 (2014).

3. R. S. Mishra and Z. Y. Ma, Mater. Sci. Eng. R 50(1-2), 1 (2005).

4. J. A. Schneider and A. C. Nunes, Metall. Mater. Trans. B 35, 777 (2004).

5. V. E. Rubtsov, S. Yu. Tarasov, and A. V. Kolubaev, Phys. Mesomech. 15(5-6), 337 (2012).

6. S. Kahl, Heron 55(3/4), 223 (2010).

7. P. L. Threadgill, A. J. Leonard, H. R. Shercliff, and P. J. Withers, Int. Mater. Rev. 54(2), 49 (2009).

8. Kwanghyun Park, Development and Analysis of Ultrasonic Assisted Friction Stir Welding Process, Ph.D. dissertation, University of Michigan, 2009.

9. V. A. Bakshaev, P. A. Vasil'ev, L. K. Gordon, Yu. A. Todin, and S. V. Vasil'ev, Blank. Product. Mech. Eng. 12, 13 (2010).

10. O. V. Sizova and E. A. Kolubaev, Russ. Phys. J. 46(2), 133 (2003). 